\title{
Collaborative Time Tracking System for Employees
}

\author{
Shweta S A \\ Department of Computer Science and Engineering, Presidency University, Bangalore, Karnataka, India
}

\begin{abstract}
Collaborative Time Tracking System for employees is believed to be found under one of many modules of a Project Management. It is crucial that the system to be developed in line with company's business objectives. CTTS implementation is an internal application developed for efficient functioning of an organization is used to monitor all the employees of a particular organization working on various projects. In this implementation timesheet may record the start and end time of each employee tasks. The timesheet contain a detailed breakdown of tasks accomplished throughout the project. This information may be used for CheckIn and CheckOut of employee time, manage activity, task assign to employee, tracking the update status of each assigned projects and updating the note and management of each tasks, Generate a Timesheet Report for all employees, Sending an email to the project manager and fetching the system IP Address of each employee. The Collaborative time tracking implementation requires development of the following tasks: Get the projects and tasks assigned to an employee. Display a form to enter the number of hours spent by an employee on a task in a day like following: It should be possible to enter the timesheet either for one task at a time and one day at a time, It should be possible to enter the time for all the assigned tasks at a time, It should be possible to modify the note and status of all project task entered earlier. Once the timesheet are entered they cannot be modified. The basic concept of this system is to improve the process of task delegation and monitoring project performance for Project Manager and Project Staff, and logging it into a nice and well-defined database.
\end{abstract}

Keywords: Time Sheet Management, Timesheet implementation, Case Study, Intranet

\section{INTRODUCTION}

Collaborative time tracking system for employees is a method for recording and tracking the amount of an employee's time spent working. The employee timesheet can report total hours worked or time spent working on a specific task or job. Employee timesheets are primarily used for payroll. The total hours worked give a record to time. To be paid. In many companies, only non-exempt employees have timesheets. This empowers an organization to precisely track and pay hours worked by material laws and control in venture administration. Worker timesheets enhance extend execution and basic leadership. Employee timesheets improve project execution, decision-making and compliance with project leader and administration. Timesheets were originally developed for employees to track the number of hours worked for all given tasks. This is used to record the start and end time of tasks or duration of the task. Employee timesheets may contain a detailed breakdown of tasks accomplished by the employee. Tracking time can reduce an organization's costs by making payroll processing more efficient. As indicated by one definition, it is a report or a program that tracks the quantity of hours work, either in one week or on a specific venture. As such, a worker timesheet is a record that you can think back on to discover how much time you spent accomplishing something. Worker timesheets were initially created for bosses to track the quantity of hours worked for finance. Worker timesheets are utilized to record the begin and end time of assignments or essentially the span of the undertaking and contain an itemized breakdown of errands achieved by the representative. Following time can lessen an association's expenses by making finance preparing more productive.

About the Modules: This consists of the services provided by the project which includes ADMIN, Manager and employee of a particular organization.

ADMIN: The admin has the details of all the employees of a particular organization and also has the details of all the current ongoing projects of the organization. The services provided by the admin are:

1. Add/Edit a NEW employee detail- The admin is responsible for maintaining a list of all the current employees of the organization and also admin should provide the employees with login id and password whenever a new employee joins the organization.

2. Add/Edit a NEW Project detail- The admin also has the responsibility to provide a project id to all the new projects added in the organization.

3. MANAGER: The manager is responsible for supervising the employees under his guidance. The main service provided by the manager is: 
Approve or Reject the time entry: Whenever the employee enters a new time sheet the manager has to approve or reject it based on the amount of work done and time spent on that particular project.

4. EMPLOYEE: The employee enters into the services by entering the user id and password given to him by the admin. The services provided are

5. Assign Task Module:- This module is accessible by Project Manager and Management only. A list of task assigns to all employees and manager needs to choose which task assign to each employee.

\section{Project Objective}

The objectives of the project are:

i. To study the business process of staff task delegation and monitoring of project performance.

ii. To design the Collaborative Timesheet Management System which include the following functionalities:

a. Assigning the task to each employees

b. Scheduling time on each modules

iii. To improve the task delegation and project performance monitoring.

iv. To formulate a management strategy for the successful implementation of the timesheet management.

\section{EXISTING SYSTEM}

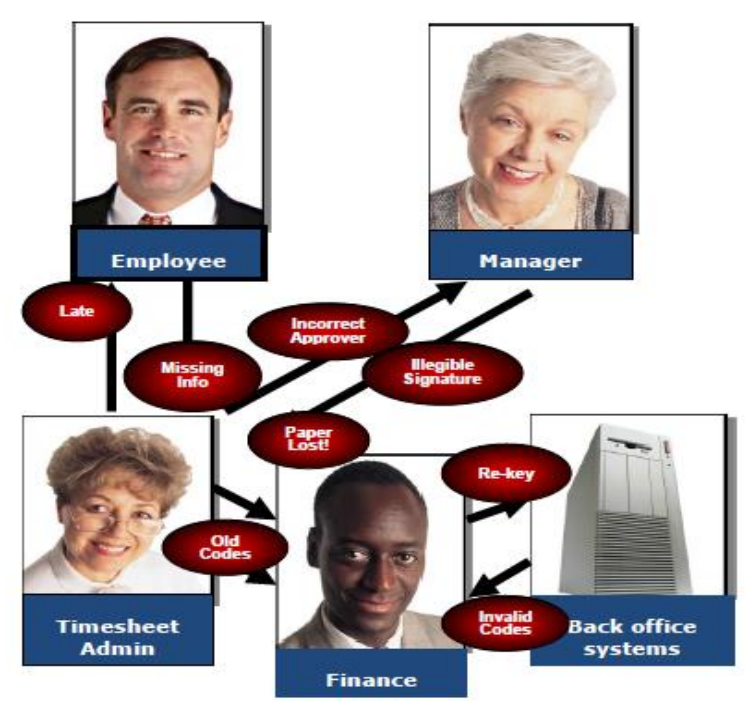

Fig 2.1 Typical problems with the process

Problem Statement: The productivity of team-based core activities of project Manager and Project Staff in The Decision Labs is hampered due to no systematic task delegation to staff \& difficulties in monitoring project performance and employees details.

\section{PROPOSED SYSTEM AND MERITS}

\section{Provides real time visibility into time recorded}

Eliminates paper forms and manual processing

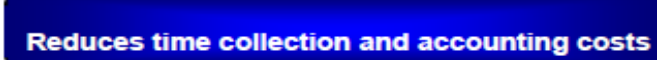

Improves management of project costs

Increases reporting accuracy

Increases employee productivity

\section{$>$ Why automate time reporting?}


Existing system needs a solution for the specified and unspecified problems. Proposed system provides solutions.

- $\quad$ The main advantage of this time sheet management is time tracking. Time tracking is mainly useful for tracking the project up to date status of all the tasks. When the assigned tasks may get delay the manager need to track the status and note of all the project tasks. Equally employees need to update the status of all the tasks.

- The most important feature of this implementation is that it is developed in such a way that it is compatible with all kinds of web screens.

\section{METHODOLOGY}

\section{Struts 2 Framework}

Struts2 is a popular and mature web application framework based on the MVC design pattern. The struts framework was initially created by Craig McClanahan and donated to Apache Foundation in May, 2000 and Struts 1.0 was released in June 2001.The current stable release of Struts is Struts 2.3.16.1 in March 2, 2014.

\section{Struts 2 Framework Features}

Here are some of the great features that may force you to consider Struts2:

1. Tag Support - Struts 2 has improved the form tags and the new tags which allow the developers to write less code.

2. Ajax Support - Struts 2 has recognized the takeover by Web2.0 technologies, and has integrated AJAX support into the product by creating AJAX tags, this function is very similar to the standard Struts2 tags.

3. Easy Integration - Integration with other frameworks like Spring, Tiles and SiteMesh is now easier with a variety of integration available with Struts2.

4. Template Support - Support for generating views using templates.

5. Plugin Support - The core Struts 2 behavior can be enhanced and augmented by the use of plugins. A number of plugins are available for Struts2.

6. Profiling - Struts 2 offers integrated profiling to debug and profile the application. In addition to this, Struts also offers integrated debugging with the help of built in debugging tools.

7. Pojo Forms and Pojo Actions - Struts2 has done away with the Action Forms that were an integral part of the Struts framework.

\section{Model 2 (MVC) Architecture}

Model View Controller or MVC as it is popularly called, is a software design pattern for developing web applications. A Model View Controller pattern is made up of the following three parts:

$\square$ Model - The model is responsible for managing the data of the application. It responds to the request from the view and it also responds to instructions from the controller to update itself.

View - It means presentation of data in a particular format, triggered by a controller's decision to present the data. They are script-based templating systems like JSP, ASP, PHP and very easy to integrate with AJAX technology.

$\square$ Controller - The controller is responsible for responding to the user input and perform interactions on the data model objects. The controller receives the input, it validates the input and then performs the business operation that modifies the state of the data model.

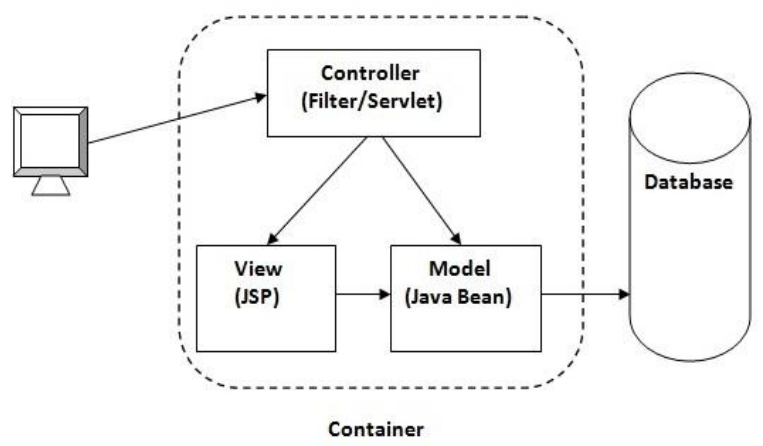

Fig 4.1 Struts2 Model 2 Architecture

\section{SYSTEM DESIGN}

The Time tracking system for employees System Design provides a detail study and analysis of the current environment including its organizational structure. Project data flow diagram and IT infrastructure and systems used are being conducted. Design process will discuss about system specification by the design and analysis. The Time tracking system design includes the Conceptual design, organizational analysis structure, Use Case diagrams, Sequence diagram, Activity Diagram, physical design. 


\section{- Interface Chart}

Chart below illustrates the overall interface available for the system. Consist of 29 major interfaces, all of which are centrally connected to CTMS main page. Due to security and operational reasons, individual users will have different type of interface access that relays to their specific operation action.

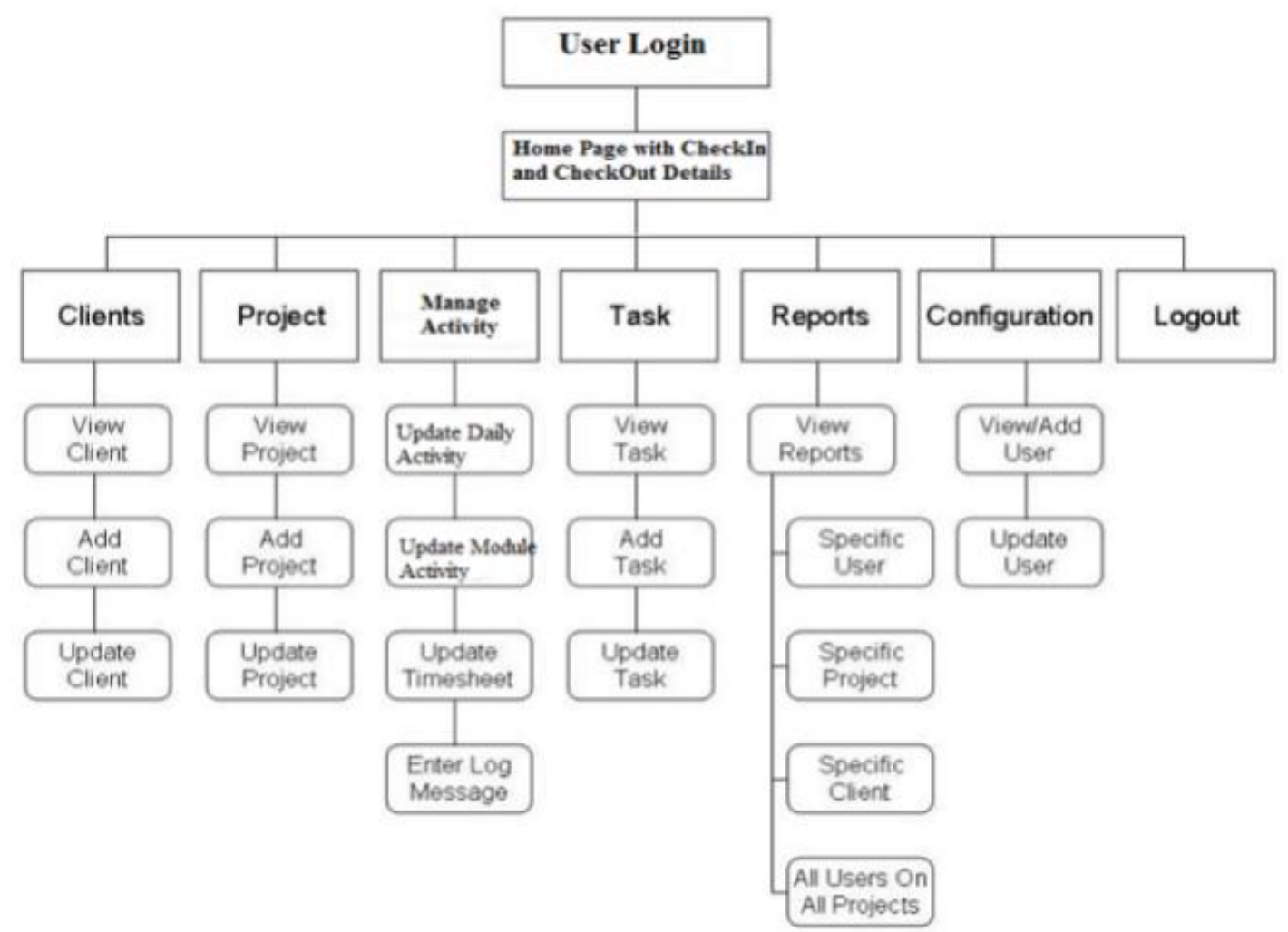

Fig 5.1 Timesheet Interface Chart

1:1:Request for Login

2:1:Manage Profile

3.1:Request for user Detail

4:1:Manage Projects Detail

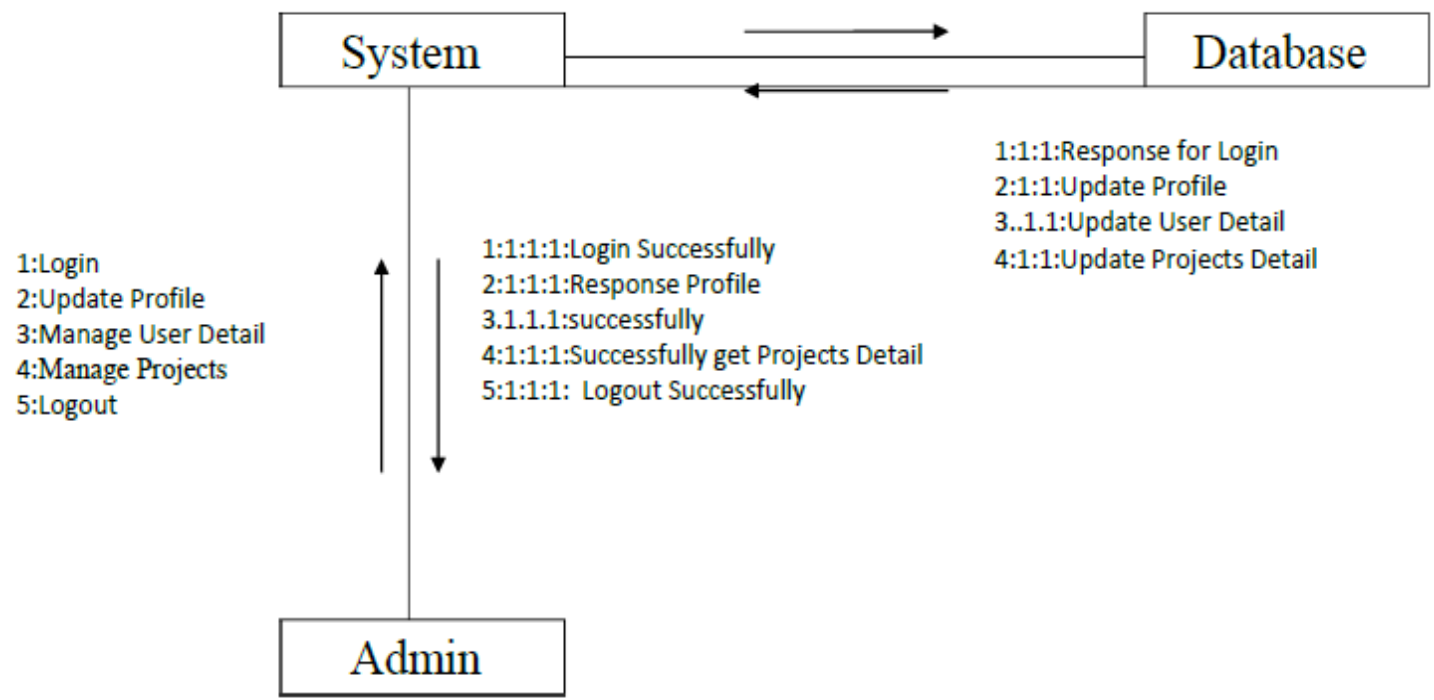

Fig 5.2 Collaboration diagram of Admin 
Sequence Diagram For Project Manager

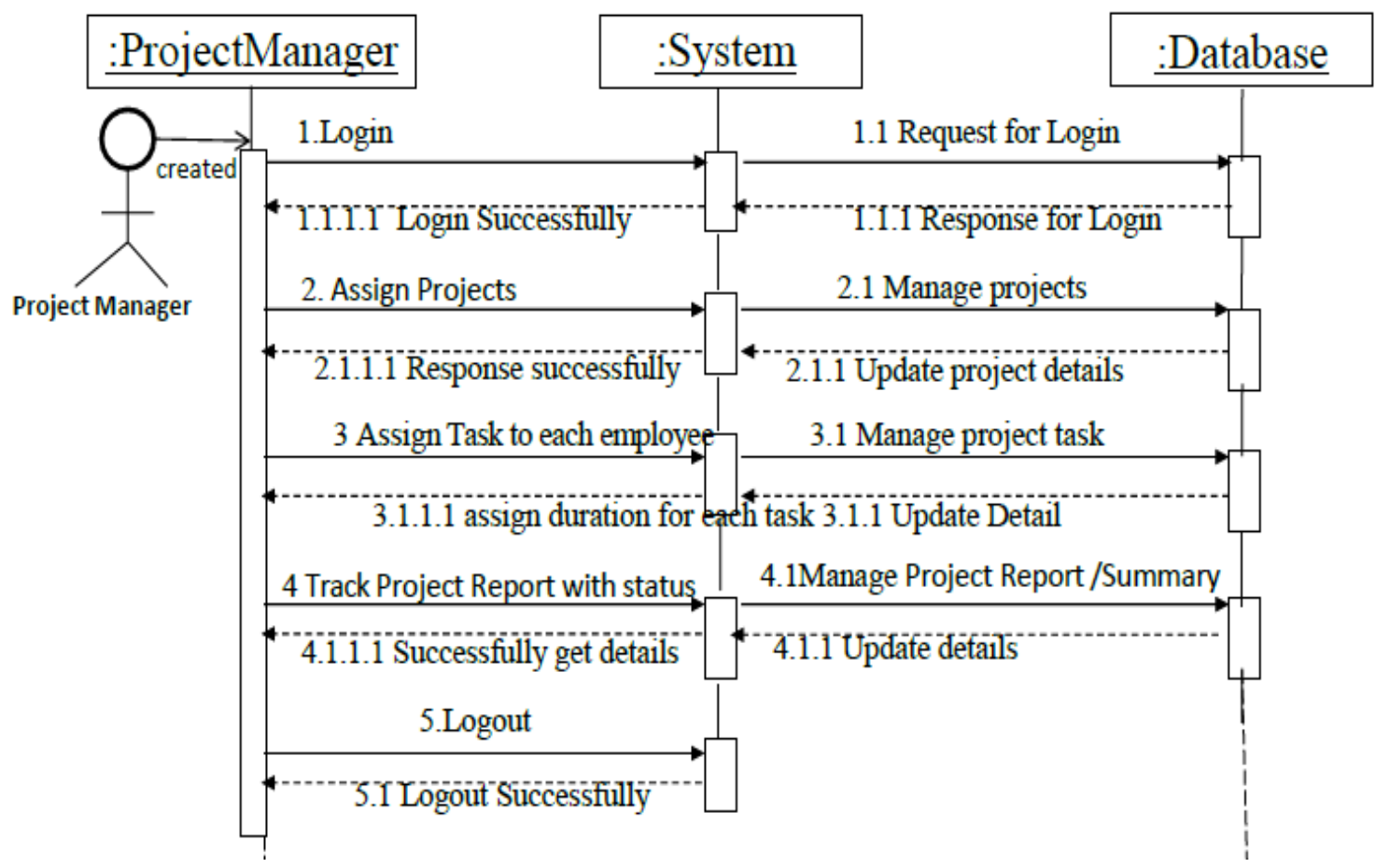

\section{IMPLEMENTATION}

There are several important of aspects need to be focused on during this implementation phase in order to ensure a successful system development. Organization can adopt many implementation strategies in order to reduce the risk of incurring serious problems during transition and implementation. In this Collaborative Time tracking system implementation, it is best to adopt the Phased Implementation where it develops the new system one module at a time. Since there are seven (7) main modules involved, the first module to be implemented will be Client followed by Project, Calendar, Task, Weekly Timesheet, Reports and lastly, System Administration modules.

1. Login Form for Employee: This has the Employee-ID and Password field and a Login button. There is no registration required for the employees. The Employee-ID and Password is assigned by the administrator only. After entering the Employee-ID and the Password, it will check in the database for the verification. If present, it redirects to the home page. Otherwise, displays an error message.

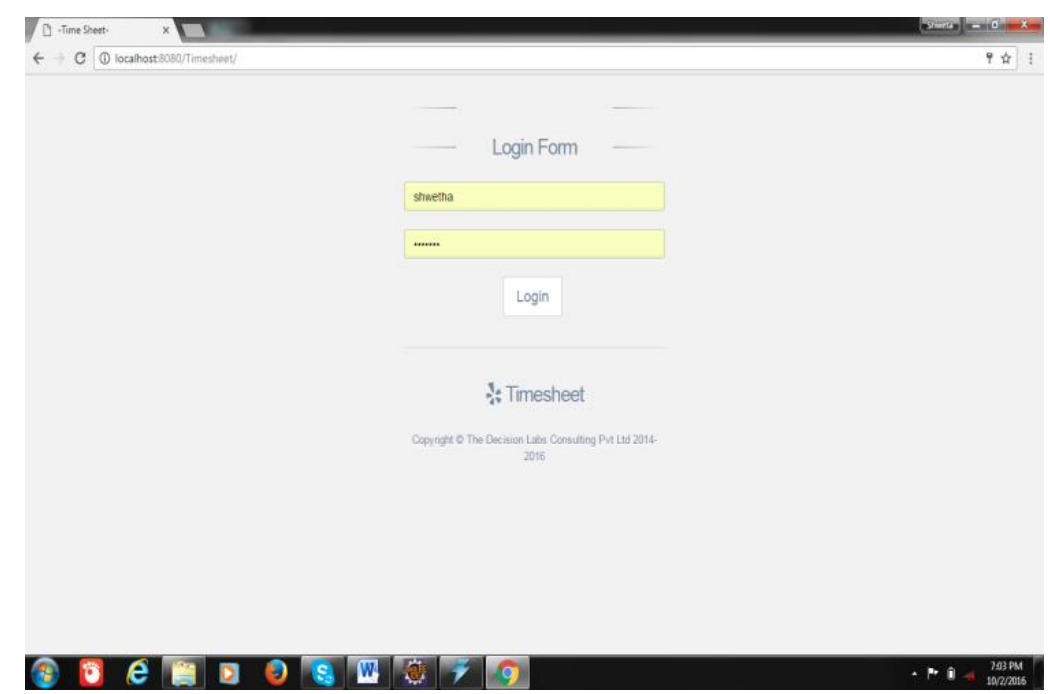

Fig. 6.1 LOGIN Form for Employee 
2. Employee: CheckIn and CheckOut for each employee (User: Project Employee)

Step 1: Login with valid Employee-ID and password, click Login.

Step 2: From the Employee Home page, click CheckIn button with valid Comment Textbox.

Step 3: At Employee Home page, click Manage Activity button it redirects to another page.

Step 4: The employee can update the note and status of assigned task in home page.

Step 5: The employee can finally logout after updating all the details.

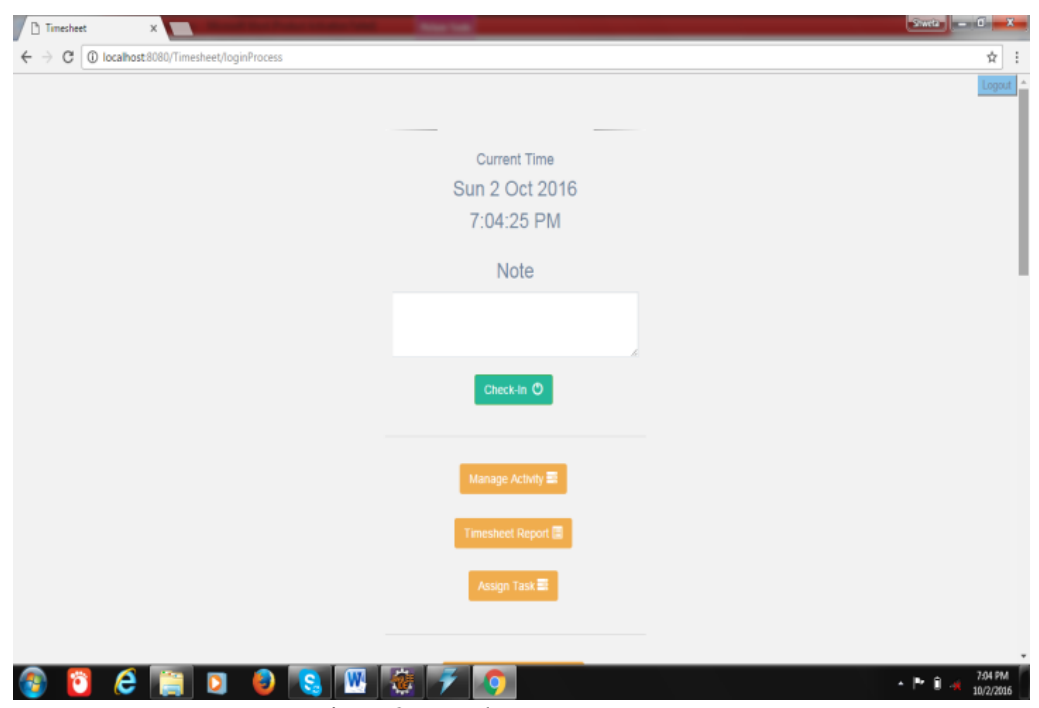

Fig 6.2 Employee Home Page

3. The Home Page has the Assigned task table. This table fields fetches from database, the different fields are created_date, task, module, duration. We have to update the status and note of the assigned task. Figure 6.3 shows the Employee Update task table.

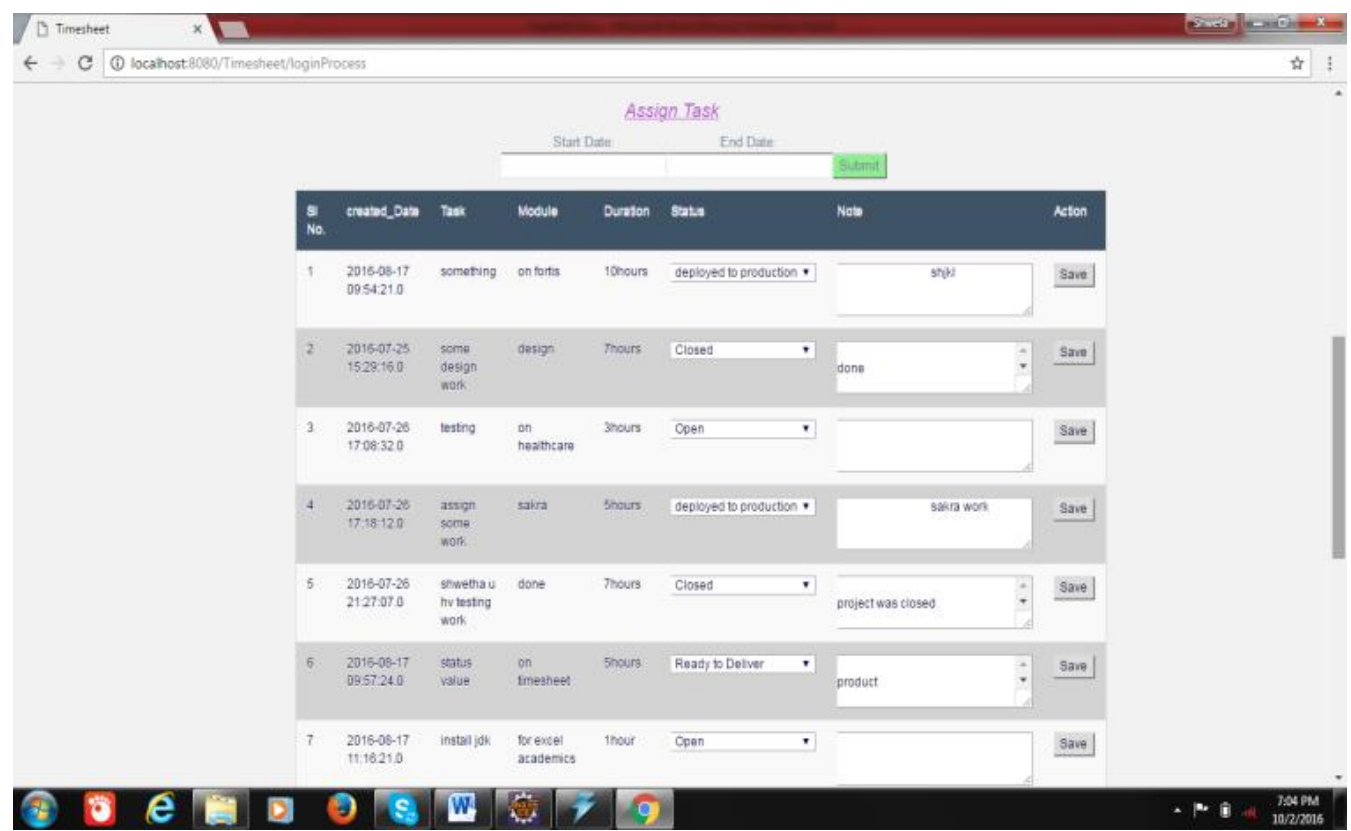

Fig 6.3 Employees Update task table

4. Manage Activity The manage activity button in home page redirects to another form where the Employee has to update all the task of that day. The data includes Activity, duration and module. The "Add Activity" button inserts the data entered in the form into the database. It displays a data table in the same page with a delete button. If we want to delete the activity we can do in same form. Otherwise, displays the error message. Figure 6.4 shows the "Employees Manage Activity Page" of the timesheet 


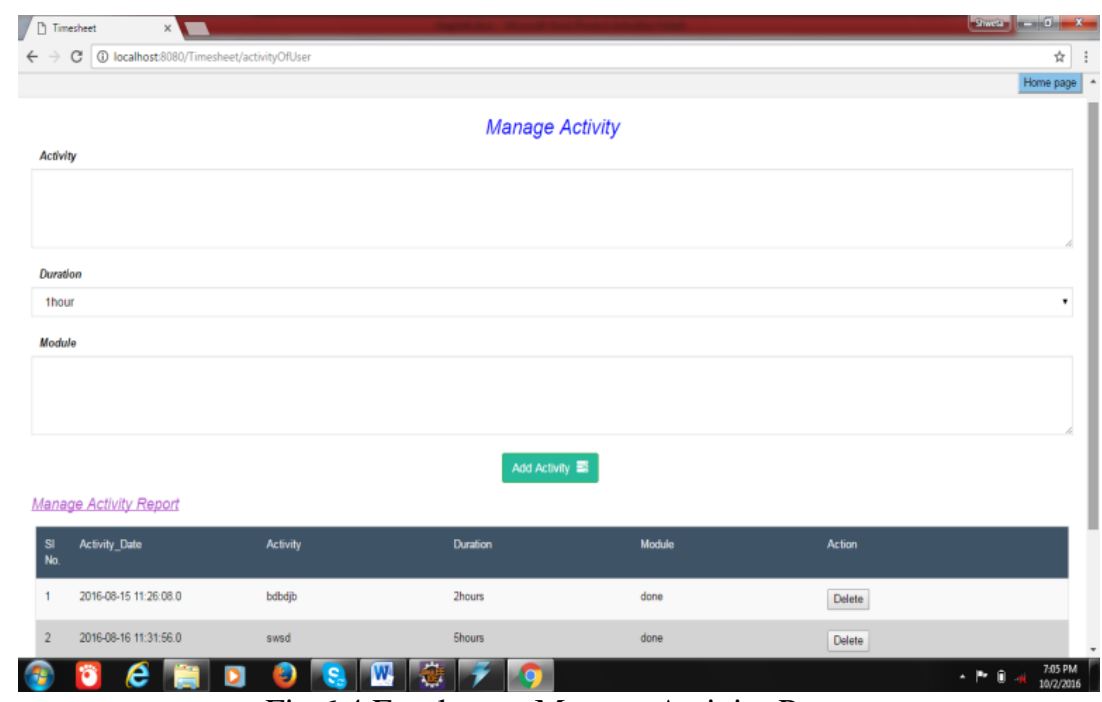

Fig 6.4 Employees Manage Activity Page

5. Timeheet Report: View Timesheet Report (User: Timesheet Report can able to view only for admin) Step 1: Login with valid Employee-ID and password, click Login.

Step 2: From the Employee Home page, click Timesheet Report button.

Step 3: It redirects to Timesheet Report page select report that user wish to analyze or generate a report for a particular selected employee.

Step 4: After the report has been generating by selected category, then we can either download in Specific format as $\mathrm{CSV}, \mathrm{PDF}$, Excel or we can directly take printout of the timesheet report.

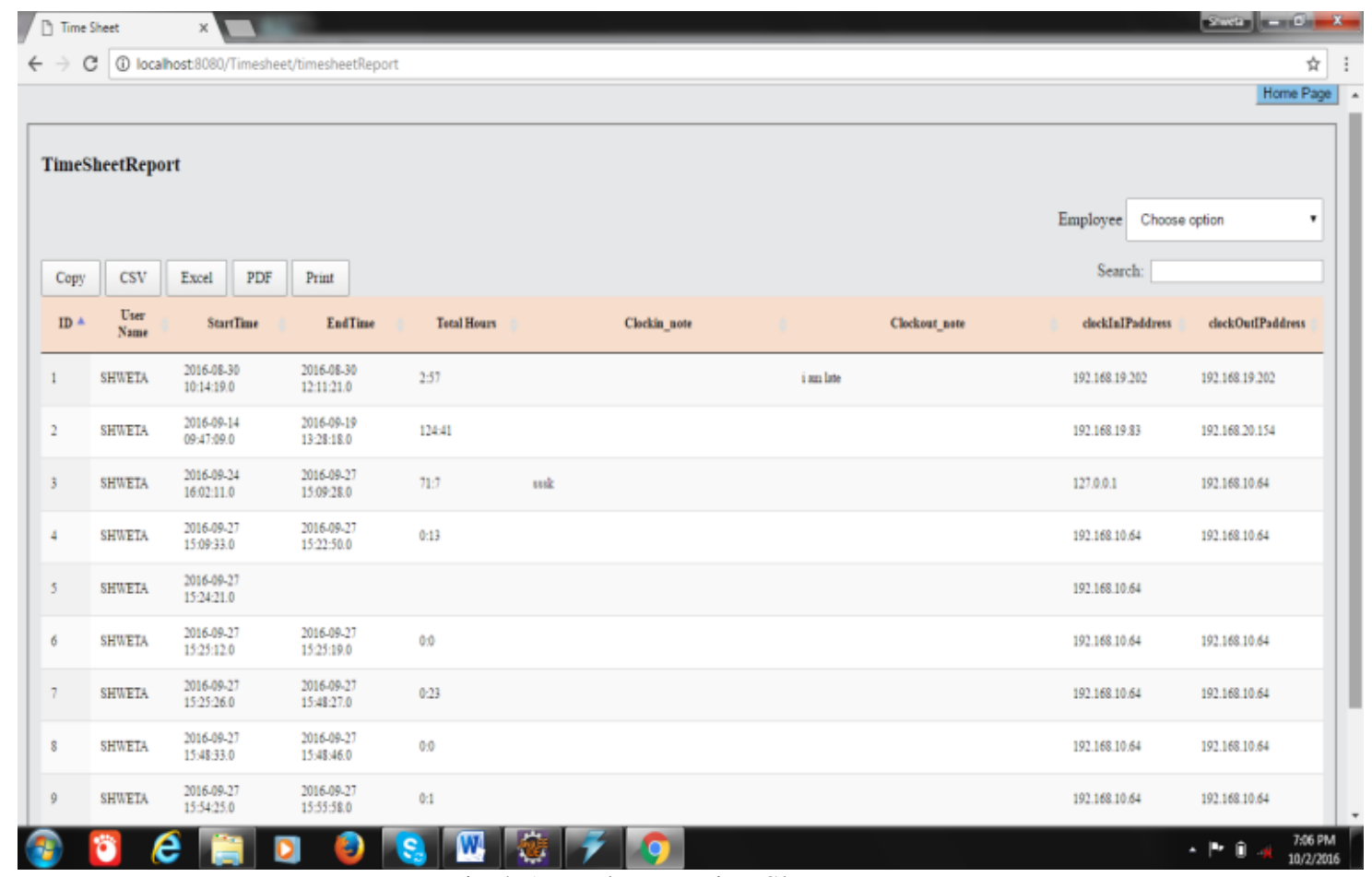

Fig 4.5 Employees TimeSheet Report

6. Assign Task: Create New Task (User: Project Manager)

Step 1: Login with valid Employee-ID and password, click Login button.

Step 2: From the employee Home page, click Assign Task button.

Step 3: At Assign task page, the manager can assign a different task to each employee.

Step 4: Fill-in the task details appropriately and selects the staffs that are involved in related project then click Add New Task. 


\section{International Journal of Advanced Research in Computer and Communication Engineering}

Vol. 7, Issue 11, November 2018

\section{Delete Assign Task (User: Project Manager)}

Step 1: Login with valid Employee-ID and password, click Login button.

Step 2: From the Project Manager Home page, The manager can see the task table in the assign task page only, he has to choose all completed older task.

Step 3: At Task Home page select task that Project Manager wish to delete, click Delete.

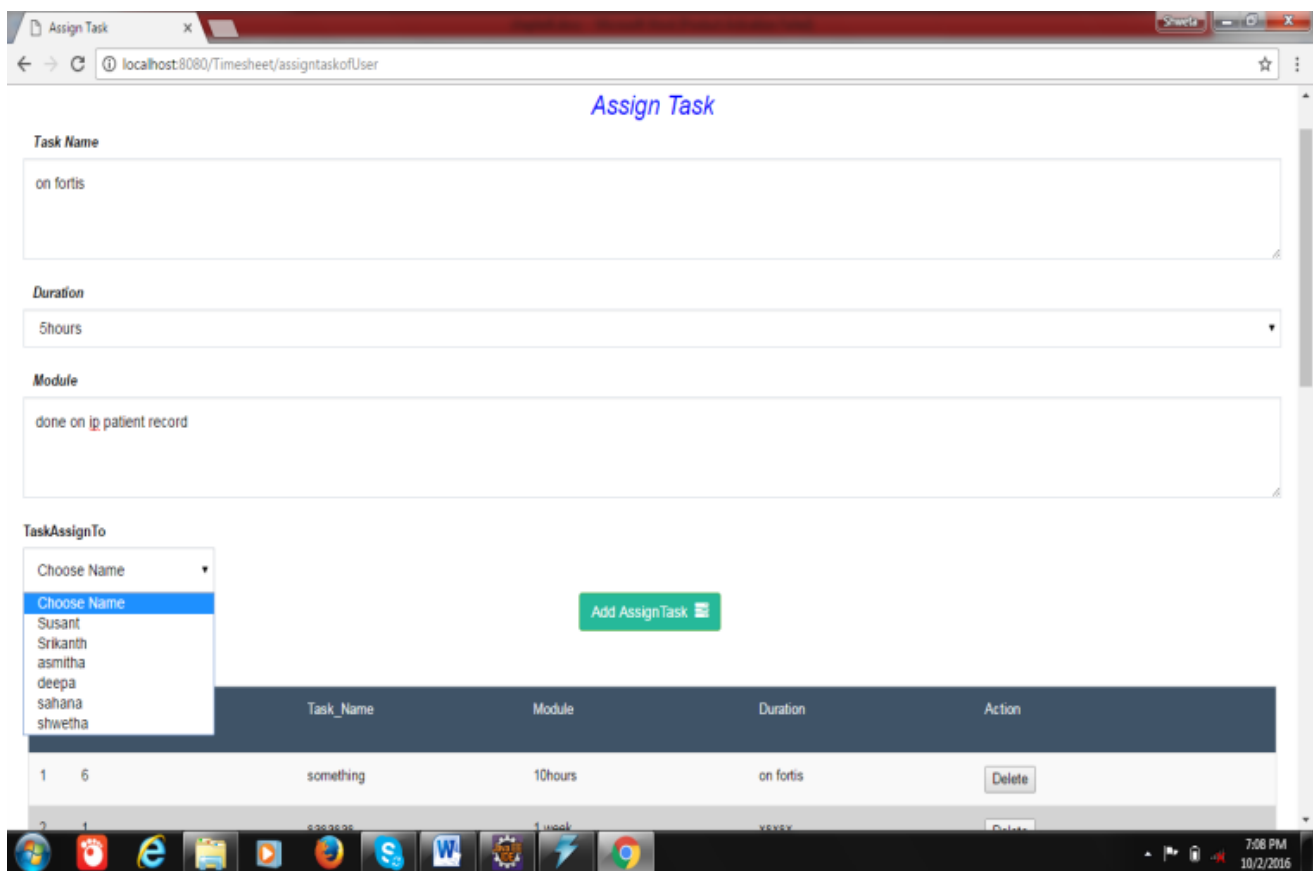

Fig 6.6 Project Manager Assign Task Page

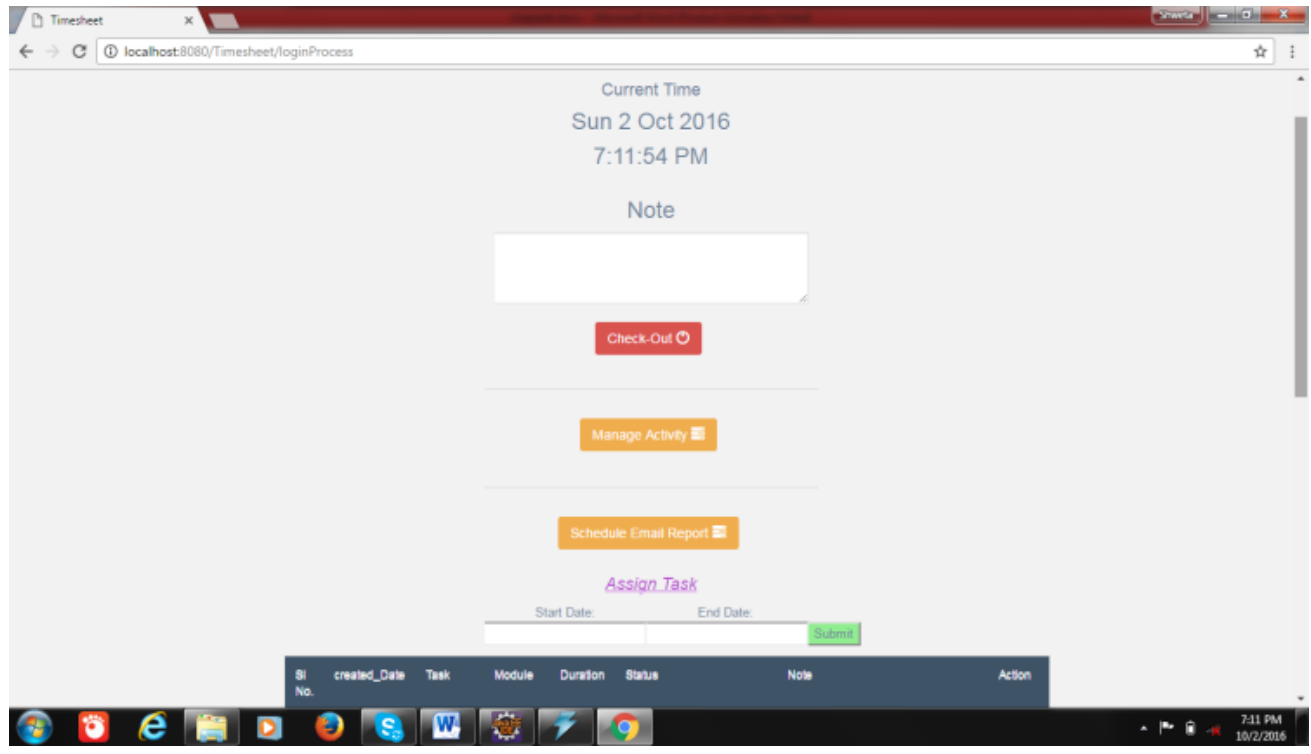

Fig 6.7 Employees CheckOut Page

\section{CONCLUSION}

Collaborative Time Tracking System for Employees (CTTS) is designed to facilitate an effectual management of an organization by providing a centralized system that can be shared amongst TheDecisionLabs Staffs. The main objective is to give direct benefit for the company such as fast retrieval of information, enhances decision making and tactical planning whilst avoiding confusion and ambiguous situation where misinterpretation could be costly both in terms of monetary and time factors. The system is considered successful as it enables users to access the system online, retrieve the information whenever they require, and execute important reports to support their daily tasks. 


\section{REFERENCES}

[1]. http://jakarta.apache.org/struts/doc1.0.2/userGuide/resources.html.

[2]. Java 2 Core Language Little Black Book by Alain Paraglyph (M.Eric.Johnson@ Tuck.Dartmouth.edu)

[3]. John Zukowski does strategic Java consulting for JZ Ventures, Inc. . His latest book is "Java Collections" (Apress, May 2001).

[4]. http://www.w3schools.com/js/js_intro.asp

[5]. http://www.javatpoint.com/java-tutorial

https://www.mkyong.com/struts2/struts-2-s--example/

[7]. The Complete Reference JSP by Phil Hanna

[8]. Java Server Pages by Barry Burd

[9]. Java Complete Reference by PatrickNaughton

[10]. David J. Barnes, “Object-Oriented Programming with Java, An Introduction”, Prentice Hall(2000).

\section{BIOGRAPHY}

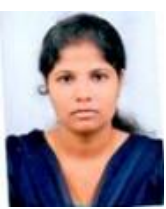

Ms. Shweta S A Completed my B.E from Bapuji Institute of engineering and technology and Master's from SJBIT College Bengaluru Affiliated to Visvesvaraya Technological University Belagavi. Currently I work in Presidency University. 